\title{
Teachers' Perspective of Distance Learning TV in Teaching Speaking During COVID-19
}

\author{
Qothrunnada Almubarokah, \\ Yudhi Arifani \\ Universitas Muhammadiyah Gresik \\ Jl. Sumatera No. 10161151 Gresik Indonesia \\ qothrunnada_180403@umg.ac.id \\ Article History: Submitted on $7^{\text {th }}$ September 2021; Accepted on $25^{\text {th }}$ December 2021; \\ Published on $30^{\text {th }}$ December 2021
}

\begin{abstract}
The pandemic situation of COVID-19 has damaged various aspects, including education. Distance learning becomes the substitute to facilitate teaching-learning, especially in rural areas. It uses television as a teaching medium to tackle the internet connection problem. Television has been used for a long time and used for entertainment purposes. However, educators start to add educational purposes, especially to learn a language. Unfortunately, television was only an additional teaching tool and was not used thoroughly. This research aims to observe the teacher's perspective of Distance Learning Television (DLTV) to teach speaking, particularly in a rural area, Thailand. The subject research is two English teachers who teach primary school in Thailand, and they use DLTV as the teaching media. The result showed that teachers have a positive perspective on DLTV as a teaching medium, especially in speaking. It contains benefits that can support students in their speaking comprehension. Furthermore, teachers have the role of facilitators and encourage students during the learning process. Despite the drawback of DLTV, it is still be taken care of by teachers by collaborative work with colleagues.
\end{abstract}

Keywords: Distance Learning Television, Speaking, Teacher Perspective 


\section{INTRODUCTION}

English teaching and learning process is essential to conduct to improve the ability of language in many kinds of communication contexts in daily life (Malaikosa \& Taopan, 2020). However, Novel Coronavirus (COVID19) has globally spread and damaged all fields, including education (Ma'rifah et al., 2021). The government has instructed schools and educational institutions to conduct the teaching-learning activity using the online method (Tafazoli, 2021). It means that the teachers and students are not able to meet face-to-face. It is such a challenging situation for developing countries. Therefore, this sudden change required teachers to quickly define, adopt, and implement the digitalized teaching methods. They should promote flexibility as well as match the student's needs (Budianto \& Arifani, 2021; Tafazoli, 2021). Therefore, it is necessary to decide the suitable media to facilitate distance learning as the response of Coronavirus. Television is one of the great choices to support this type of learning since it contains several benefits and is used worldwide.

Television has been used worldwide since a long time ago. According to the Australian Bureau of Statistics (2001), 99.2\% of Australian households had one television at home at least. Moreover, in a United States study, 96\% of respondents stated that their children watched television every day. Furthermore, $81 \%$ of respondents argued that their children watched television for an hour or more in a day (Michael Cohen Group, 2007). Further research by Rideout (2003) revealed that the United States children spend an average of 3-5 hours a day viewing television. A recent study of children's television programming in Canada found that Canadian preschoolers (two to six years old) spend nearly 19 hours per week watching television (Centre for Youth and Media Studies, 2010).

In addition, in terms of the benefits of television, several studies have proven that excellent educational programming can assist that improves children's initial literacy as well as literacy skills (B. Samuels, 1970; Bachrach et al., 2009; Hubbard, 2004; Kendeou et al., 2005; Linebarger \& Piotrwoski, 2006; Linebarger \& Wainwright, 2006; Moses, 2008; Singer, 2002; Stipp, 2003; Sutherland, 2004). Another issue that can be solved by television is internet connection lacking. In addition, there is also an issue in purchasing digital devices in developing countries (dos Santos et al., 2006; Tafazoli, 2021). A report by the Statistical Centre of Iran in 2017 showed that $28 \%$ of Iranians lack internet connections (Tafazoli, 2021). It means that many of the population will struggle in implementing online learning.

Therefore, the government tries to utilize television as a learning medium. Brazil has become one of the countries that are studying Digital Television (DTV) to meet the needs of the county by the name of "SBTVD (Sistema Brasileiro de TV Digital: Brazilian Digital TV System)" (dos Santos et al., 2006). Similarly, Thailand also implements the strategy to use television as the alternative for learning media. DLTV (Distance Learning Television) 
is running under the collaboration of Her Royal Highness Princess Maha Chakri Sirindhorn: Royal IT Projects and Distance Learning Foundation. The DLTV can be applied in schools to increase the learning opportunity for rural students. It shows that television programs can be an alternative to demonstrate distance learning.

Teaching using television has been applied in several aspects of language, including vocabulary, grammar, reading, listening, and learning retention (Lin \& Siyanova-Chanturia, 2014; van Lommel et al., 2006). However, the former studies contain some shortcomings. Television only became a "teaching tool" in which the role is subordinated. Moreover, none of them has discussed the use of television to improve speaking skills which is also a crucial communicative skill. Therefore, the current research investigates teachers' perspectives of the television's use in distance learning programs to increase speaking ability in Thailand.

During the pandemic situation, teachers need to optimize the use of various teaching media. Therefore, the distance learning method has been a substitution for online learning. One of the methods is by conducting a live video conference. However, it cannot proceed because of poor connection and overuse, especially in rural areas (Schneider \& Council, 2021; Stelitano et al., 2020; Tafazoli, 2021). It leads to a crucial barrier to overcoming the COVID19. However, the challenge of internet connection may come from different aspects, both from the teachers and the students. Similarly, lack of internet connection has caused several issues, such as limited dial-up speed that causes buffering (Srivastava, 2020). It restricts the ability to acquire information and makes the learning activity unable to run smoothly.

Television is one of the one-way media communications that has been used since a long time ago. The essential function is sharing the information both on a national and international scale. Furthermore, nowadays, television is also used for the learning process, basic educational management (Grade 1 to 11), educational management for professional development, the development of life skills in social and community development (Fell \& Lukianova, 2018). In addition, educational television program promotes free service and non-formal education.

When students must study remotely due to the COVID-19 pandemic, the Distance Learning Foundation cooperated with the Ministry of Education in Thailand to promote distance learning and teaching programs using digital television systems. The National Broadcasting and Telecommunications Commission (NBTC) has agreed to allow students access to education through 17 TV channels consisting of 15 that involve basic education programs, channel concerns distance education, and another is related to vocational education (Tortermvasana, 2020). The DLTV (Distance Learning Television) was established to solve several problems, including the lack of teachers in a specific field in rural areas. In addition, it also tackles the issue of the lack of internet connection during pandemic (Fadhilah \& Sastramiharja, 2019).

Teachers' Perspective of Distance Learning ... 
Moreover, in terms of the learning process, it is shown that television can assist students in learning in various ways. Van Lommel et al. (2006) concluded that the vocabulary skill is easier to acquire by subtitled-movie television. Similarly, Koskinen et al. (1986) revealed closed-captioned television as a medium for reading instruction with deaf students. It showed a significant improvement in reading comprehension, vocabulary retention, and students' motivation.

Another research by Huang \& Eskey (1999) examined the aftermath of closed-captioned TV (CCTV) on the listening skill of intermediate English as a second language (ESL) students. CCTV can support ESL students' comprehension in listening and other aspects, including general comprehension and vocabulary acquisition. Nonetheless, these studies are inadequate since none of them investigated the use of television in teaching speaking skills and solely used television as an additional teaching medium.

Consequently, this current research aimed to investigate how the teachers use the DLTV to teach speaking and scrutinize the teacher's perspective of DLTV as the television's role has become the teaching tool. With the integration of technology in the $21^{\text {st }}$ century, teachers must utilize the technology to increase their effectiveness. By conducting meaningful teaching-learning, teachers can construct a way to connect the learners to the knowledge and its application in their actual condition (Ertmer \& OttenbreitLeftwich, 2010). Moreover, technology can support teachers to teach by providing routine materials, developing a better approach in teaching, and altering the learning context and content (Lawless \& Pellegrino, 2007). Therefore, there is an integration between teachers' knowledge, belief, and culture (Ertmer \& Ottenbreit-Leftwich, 2010). That is why the teacher's perspective is significant for investigating the importance of technology use in the teaching-learning process. Therefore, this research was under the following research questions: 1). How are teachers using the DLTV to teach speaking during the COVID-19 pandemic? 2) How are teachers' perspectives in teaching speaking using DLTV?

\section{METHOD}

This research belongs to the qualitative case study approach, which focused on collecting data through interviews. The interview questions are adopted and modified from Davidson et al. (2014), which focuses on the teacher's view on using technology as an instructional tool. Furthermore, the researchers employed some alterations to fit the research focus on teaching speaking with DLTV. 
Two English teachers were examined related to their perspective in using DLTV in teaching speaking. The teachers were chosen by their teaching experience, particularly in the familiarity of technology in teaching and learning activities. In addition, the decision was found as one of the teachers was the mentor of the researcher's internship program in Academic Collaboration in English Learning Development between Thailand and Indonesia from July 2nd, 2020 - to November 16th, 2020. Another teacher was from the researcher's fellow's mentor, who also has exposure to teaching English with technology. The research was conducted during the internship program and focused on speaking at the elementary level.

Due to the pandemic of COVID-19, there is the main change that the researchers do which is replacing face-to-face focus group interviews with online-based digital interviews using platform zoom meeting and LINE voice-recording feature, following the research conducted by Kucirkova et al. (2020). The researchers interviewed the participants to know their attitudes towards the teaching method. Also, the researchers want to know and the challenges they face when applying the DLTV.

The case study design is chosen for this study since it provides an intensive description and analysis of a phenomenon or social unit such as an individual, group, institution, or community (Ary et al., 2018). Furthermore, the researchers used "how" and "why" questions since it is the more preferred method of research (Yin, 2009). Therefore, the researchers have a deep analysis of the phenomenon. Furthermore, it can define the different characteristics of each case. In addition, by doing these steps, it is hoped that the researchers could inform future studies that experience the same situation (Kucirkova et al., 2020).

Online interviews were conducted using open-ended questions and recorded by the researcher's device. The interviews were conducted after the participants had finished teaching, so they have more plenty of time. The participant had separate interviews to avoid interfering with their answers. Each interview lasted for approximately 20-30 minutes. Hatch (2002) argued that interviews provide researchers with insights into participants' perspectives. Therefore, the interview data give valuable information for designing professional development plans to solve the problems revealed in the interviews.

Moreover, the researchers immediately transcribed the data after the interviews had finished, as suggested by Hatch (2002). Once the data were obtained and collected, the interviews were transcribed and coded according to the themes and categories, researchers stored them in a safe location. The questions give clear and detailed information to answer each study question. Janesick (2004) argued that it is essential to conduct interviews. Hence, we can get rich and meaningful data in a qualitative study. The video recording was stored, and researchers sent the documentation to each participant to conduct an individual member checking where they are given a chance to validate or add more information to increase the data accuracy. Furthermore,

Teachers' Perspective of Distance Learning ... 
the triangulation process of the data and multiple sources of evidence strengthened the study's validity and can make it more varied based on the suggestion by Yin (2009).

The data are analyzed by employing the typological method. Since the researchers only rely on interviews solely as the sole source, the data must be narrow. Also, it should be specific on the outcomes needed. The study aimed to capture the attitude of individual teachers around particular topics. Therefore, the typological study is an appropriate strategy to assist them in grouping the data based on the research objectives (Hatch, 2002).

The procedure of analyzing the data was following Hatch (2002) that began with identifying the aspects that will be analyzed related to teaching speaking with technology. Moreover, they conducted a deep reading and looked at the patterns, correlations, and themes of each category. The categories include the easiness of DLTV, challenges during the implementation, aspects that affect DLTV, and teacher's perspective and their roles in teaching using DLTV. Furthermore, researchers decided whether the category by data then correlated it. Once they got the correlation among the categories, researchers wrote the pattern in a one-sentence generalization and chose the supporting data.

\section{FINDINGS AND DISCUSSION}

The data were collected from two teachers from a different school in a rural area, Thailand. Both are teaching primary school. The finding focused on observing the use of DLTV and the teachers' point of view regarding the DLTV as teaching media to teach speaking during the pandemic. The interview questions aimed to find how and why the subjects view the DLTV as a teaching media to teach speaking during pandemic COVID-19. The excerpts below explain more about participants' responses. The participants' identity is disclosed with initial T1, which means Teacher 1, and T2 means Teacher 2.

According to (Arifani et al., 2021), excerpts are used to provide participants' responses. In line with the research questions, the result sections are grouped into two categories. The first is the use of DLTV in teaching speaking during the pandemic of COVID-19. This category includes the easiness of DLTV, challenges during the implementation, and aspects that affect the use of DLTV. The second category is teacher's perspective and their roles in teaching using DLTV. 


\section{The use of DLTV in teaching speaking during the pandemic of COVID-19}

a. The easiness of DLTV

Excerpt 1

R: $\quad$ I want to ask about your own opinion, more specifically in teaching speaking in the classroom using DLTV. In terms of English teaching speaking, how do you see the DLTV for the learning activity?

T1: I think it is a new teaching innovation for the students they can easily study at DLTV, especially in this pandemic where teachers cannot see the students directly.

R: Do you combine the textbook material with DLTV when you teach speaking in your classroom?

T1: Yes, because it can match with the content of students' lessons. It is easy to teach students because it has connected with the students.

R: So, does the content of DLTV is match with students' textbooks?

T1: Yes, it is.

\section{Excerpt 2}

R: $\quad$ I want to ask about your own opinion, more specifically in teaching speaking in the classroom using DLTV. In terms of English teaching speaking, how do you see the DLTV for the learning activity?

T2: It is good for the school if the teachers could not make the class in this distance learning. So, it is a good innovation from the government to establish the DLTV, especially to teach the students and to teach new things.

R: $\quad$ Do you combine the textbook material with DLTV when you teach speaking in your classroom?

T2: $\quad$ There is the material and content scheduled from the central area

The following excerpt demonstrates the accessibility of DLTV in conducting the teaching activities. The questions above trigger the teachers to explain how they utilize DLTV to deliver the materials. The first teacher stated that DLTV is an innovation that helped students during the pandemic. Since the outbreak, students cannot study regularly and must rely on the limited material given by teachers. With DLTV, they have more chances to access the school lesson easily. In addition, DLTV is flexible and easy to use since there will be more various kinds of teaching resources. If the students 
want to follow the subject in real-time, they can stream it because it is broadcasted through the satellite (Fadhilah \& Sastramiharja, 2019). Therefore, students can watch it from local television and online.

In addition, the participant also stated that students are supplied with printed book materials. They are synchronized with DLTV to guide and track students' performance of their activities or the exercise. The printed module comes from the government. Therefore, most all schools have the same module. The module is available for the whole class from $1^{\text {st }}$ to $6^{\text {th }}$ grade, and the themes follow their level in elementary school. Despite the easiness of the DLTV, teachers still face several barriers during the teaching process as they cannot take control thoroughly during the distance learning activity. The following excerpt will support the data related to the challenge of the DLTV implementation.

b. Challenge during the implementation

Excerpt 3

R: Now, let's talk about the challenge or difficulties during teaching speaking using DLTV.

T1: I think the challenge of teaching is how can you get the students to be focused on the content. That is because sometimes the students were too engaged in a fun activity and they forgot to be focused on the material. This is why sometimes I create follow-up speaking activities afterward so, the students can be focused.

R: $\quad$ So, it is hard because you need to keep students engaged yet focused on using DLTV?

T1: $\quad$ Yes

R: What about the other challenges? Is it just one or do you have another challenge in teaching speaking using DLTV?

T1: I think the challenge for me is to make everybody in the classroom study.

R: $\quad$ How do you overcome the challenge in teaching speaking using DLTV?

T1: I try to know the interaction between students and teachers for teaching speaking.

R: $\quad$ So, do you talk with another teacher to find the solution (how to create an engaging and focused classroom, even though you use DLTV to teach?

T1: Yes, like that

R: Do you think it is helpful for you?

T1: $\quad$ Yes, it is 


\section{Excerpt 4}

R: Now, let's talk about the challenge or difficulties during teaching speaking using DLTV.

T2: Yes, when your students are not focusing on having the class, and there is no teacher to supervise because it is far, it can be dangerous.

R: $\quad$ How do you overcome the challenge to teach speaking using DLTV?

T2: Usually, I do some evaluation pretty often after school

The excerpt investigates the barrier when implementing the teachinglearning process. According to the participants, the main issue in using DLTV is maintaining the student's focus on the lessons. The excerpt revealed that both teachers encountered the same problem. It makes them work harder to keep the students focused. Especially, when they sit in front of the television they can get easily distracted and forget the fundamental purpose of learning. For instance, they can misunderstand the teachers' instruction.

To define technology, teacher participants encounter several obstacles during utilizing the technology (Megawati et al., 2020). Therefore, to overcome the problem, the teachers give a follow-up teaching activity to ensure that the students followed the class well and measure their understanding. Other than that, T2 also works with other teachers to share the same struggle and find the solution together.

\section{c. Aspects that affect DLTV}

\section{Excerpt 5}

R: $\quad$ How much time do you use the DLTV in teaching speaking in the classroom?

T1: $\quad h m \ldots$ about one hour, sometimes 50,30 , or up to one hour

R: How do you enjoy using DLTV to teach speaking? And what's the effect on the students?

T1: Yes, I enjoy it, and it makes students have many learning sources, especially for speaking.

R: Do you think DLTV is helpful for the teaching process?

T1: I think it is helpful. Sometimes I do not have enough time to teach students, I can use DLTV to teach, and I found it is useful. And if the school cannot open the class because of the pandemic, we can use the DLTV. DLTV is also helpful during this pandemic to help both students and teachers to conduct distance learning, you don't have to meet face to face, but we still can learn.

R: In your opinion, can DLTV increase teaching and learning of speaking? 
T1: Students can speak a single communication sentence from DLTV, but they can also talk with the teacher in the classroom.

Excerpt 6

R: $\quad$ How much time do you use the DLTV in teaching speaking in the classroom?

T2: $\quad$ I teach from 8.30 am to $1: 30$ pm every day

R: How do you enjoy using DLTV to teach speaking? And what's the effect on the students?

T2: I enjoy and even gain more knowledge from it

R: $\quad$ In your opinion, can DLTV increase teaching and learning of speaking?

T2: Yes, especially if the students practice and work hard.

The excerpt showed that teachers teach for sixty to ninety minutes each day. Based on the interview, the participants stated that they enjoy teaching with DLTV as they can give students many activities to learn, especially during speaking. DLTV also provides them with numerous teaching resources that synchronize with the school textbooks, and they can develop follow-up activities for the student. Moreover, it helps the teachers when they cannot make the class on time. For instance, in the case of T1 in excerpt 5, she uses DLTV to help the students understand the material. In addition, DLTV helps the students increase their communication skills as they can imitate expression in DLTV and then demonstrate it with their teachers. Therefore, DLTV gives teachers and students new things to learn.

\section{Teacher's perspective and their roles in teaching using DLTV.}

d. Teacher's attitude towards DLTV

\section{Excerpt 7}

R: $\quad$ How do you see about DLTV in your What do you think about DLTV?

T1: I think DLTV of Thailand is a technology that is used to teach from distance and used by some schools. And I think it is good to teach students many skills such as speaking.

R: What about gender? Is there any difference in teaching using DLTV for male and female teachers?

T1: Women and men teachers are not different because they have a technique to teach 


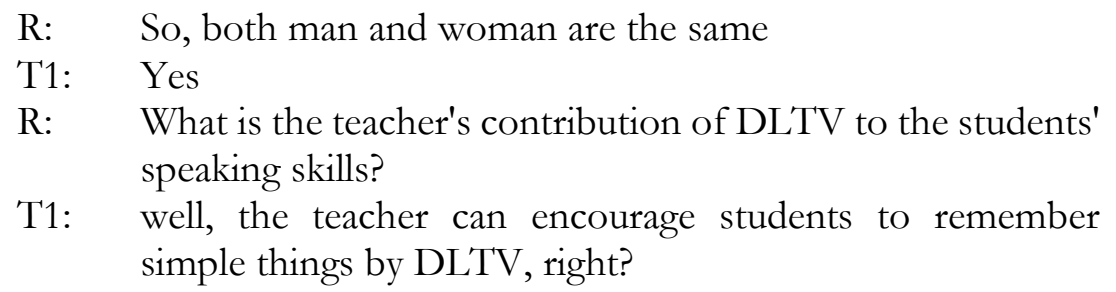

Excerpt 8

R: How do you see about DLTV in your What do you think about DLTV

T2: $\quad$ I have three years of teaching experience, and DLTV has helped me a lot. Especially nowadays in the pandemic situation.

R: What about gender? Is there any difference in teaching using DLTV for male and female teachers?

T2: $\quad$ No, there is no difference

R: What is the teacher's contribution of DLTV to the students' speaking skills?

T2: Teachers can also help to teach some students when they do not know about certain words or sentences.

In terms of perspective, both teachers show a positive way of viewing DLTV to teach speaking in English. Female and male teachers also have the same capacity for using DLTV in teaching activities. T1 stated that the DLTV is a helpful resource to teach English skills particularly in speaking. Meanwhile, T2 has been teaching for three years. She argued that DLTV helped her teach English, and it is much more helpful during this pandemic era to conduct distance learning. Moreover, teachers' role in teaching activity using this media is to become a facilitator to encourage students to explore more by themselves and guide them when the students get lost.

Moreover, four aspects influence this study, including the easiness of DLTV, the challenge during the implementation kinds of attitude that affect DLTV, and teachers' perspectives in teaching using DLTV. The overall result showed that DLTV is advantageous for teachers to conduct a teaching activity especially speaking.

The initial discussion argues with the easiness of DLTV to assist the students in distance learning, particularly in teaching speaking. From the result, DLTV is an innovation that helps them in distance learning. During the pandemic, students are limited by the study materials. With the flexibility and accessibility of DLTV, they can learn individually anywhere. Since DLTV can be accessed live through broadcast and online, students can learn easily. If students have missed the live broadcast can watch it through the website of the DLTV satellite on https://dltv.ac.th. In addition, to align the students' understanding, teachers should assist them during the learning activity. 
According to Bates (1988), letting the students study themselves without any assistance would not develop their skills.

Therefore, students are provided with printed modules integrated into the government curriculum.

The second discussion is related to the challenge faced by teachers during implementing DLTV in teaching speaking. Moreover, physical faceto-face learning activity is challenging in distance learning. Hence, television could be an adequate substitute. However, even though the DLTV is flexible and easy to access, it is inevitable that DLTV still contains disadvantages. The result found that both teachers experience the same problem, which is keeping the students focused and not being distracted by the entertainment purpose of the television. Bates (1988) explained that the characteristics of television contain lots of information density as the result of the amount and kinds of symbol systems it carries simultaneously. In addition, television combines words, moving images, events, animations, and even texts. Therefore, television has enchanting features that other media lack. It could be a challenge to keep the students on study purpose. Based on the research by Webb (2015), it is because television is an entertainment form rather than a learning source. It will lead them to enjoy the entertainment part only, without paying attention to the actual purpose of learning (Lin \& SiyanovaChanturia, 2014). Hence, it is likely that students will get distracted easily and not focus on the initial learning purpose. Thus, teachers need extra work to overcome this challenge. The findings reveal that working together with other teachers can help them find the solution. A study by Hargreaves (2000) shows that a group of teachers that work together can accomplish any task much better than an individual. It happens because this teamwork assists teachers in collecting various resources, sharpening the sense, and improving the response towards demands on their practice. More importantly, teachers can share their experience in a field so others can learn from it. Moreover, teachers conduct a follow-up activity to ensure the students are on the right track and not overwhelmed.

The third discussion deals with the aspects that affect the DLTV in teaching speaking skills. The result initially stated the duration of teaching and how teachers enjoy the DLTV. With that long duration, that teacher needs to think about the activity that can keep them engaged to learn. Research by Webb (2015) concluded that television contains the value that provides the spoken input of the L2 massively. Moreover, it also develops other learning aspects, including vocabulary knowledge and listening comprehension. The interview result supported the positive effect of the television program in supporting the distance learning activity. It helps teachers because DLTV can make students imitate simple sentences and expressions. It will be beneficial for them to practice their speaking skill.

The ultimate discussion highlighted how teachers view DLTV as a helpful teaching media. More importantly, the teacher plays an essential role in teaching speaking in the teaching-learning process. In terms of gender, the

Teachers' Perspective of Distance Learning ... 
finding unveiled that there is no difference between male and female teachers on using DLTV to teach speaking. This media allows teachers to gain more teaching resources and make students learn regardless of the distance. Moreover, teachers see DLTV trigger students who are doing distance learning, especially on this occasion. Furthermore, according to the finding result, students can imitate various words and expressions used on the TV. It will also enrich their vocabulary. Since the government has prepared the printed module for DLTV, the students can follow along with the DLTV and synchronize it with their modules.

Even though teachers cannot directly conduct face-to-face during distance learning, they still play an essential role in teaching-learning. The finding results explained that teachers encourage the students in the learning activity and guide them. Furthermore, according to Char et al. (1993), teachers can develop the learning by demonstrating the learning goal, encouraging students to be confident and proud of themselves. They also assist them in using the printed material. They can also show the connection between television and daily life. It would build a good correlation, where students can relate what they have learned and implement it. Finally, it will strengthen their interest in further learning. Therefore, it will result in the improvement of students' skills.

\section{CONCLUSION}

From the data collected by interview using an online platform, English teachers in Thailand have an excellent perspective towards the DLTV as a solution for conducting distance learning activity during pandemic COVID-19. It happens as the DLTV is easy and flexible to be used by both teachers and students because it optimizes the use of television satellite and combines it with printed materials for the students. Thus, the students can improve their speaking ability since they can easily imitate words and expressions used by the DLTV. Therefore, it will also enrich vocabulary knowledge. Despite the challenges during the implementation, DLTV still becomes an adequate substitute for the physical face-to-face meeting. Especially during distance learning. With good collaboration among teachers, they will be able to tackle the barriers. Finally, it is recommended for further research to investigate whether this teaching media is applicable for higher education as they also have developed their skill much more than at the primary level. 


\section{REFERENCES}

Arifani, Y., Barianty, T. N., \& Paulina. (2021). EFL learners' cognition process: A case study of two ASD learners with different IQ levels. Journal of Asia TEFL, 18(2), 657-665. https://doi.org/10.18823/asiatefl.2021.18.2.20.657

Ary, D., Jacobs, L. C., Irvine, C. S. K., \& Walker, D. (2018). Introduction to research in education (10th ed.). Cengage Learning.

Australian Bureau of Statistics. (2001). Australian social trends. https://www.abs.gov.au/AUSSTATS/abs@.nsf/allprimarymainfeat ures/2B10DB7CF54F4A76CA25709F0025EF97?opendocument

B. Samuels. (1970). The first year of sesame street: $A$ summary of audience surveys, 8. Children's Television Workshop.

Bachrach, E., Houseman, L., Priedeman, M., \& Goodman, I. (2009). Sid the science kid: Season 1. Summative evaluation. Goodman Research Group.

Bates, A. W. (1988). Television, learning, and distance education. Journal of Educational Television, 14(3), 213-225. https://doi.org/10.1080/0260741880140305

Budianto, L., \& Arifani, Y. (2021). Utilizing WhatsApp-driven learning during covid-19 outbreak: EFL users' perceptions and practices. Computer-Assisted Language Learning Electronic Journal (CALL-EJ), 22(1), 264-281.

Centre for Youth and Media Studies. (2010). A national study of children's programming in Canada. Department of Communication, University of Montreal.

Char, C., Miller, B., Isaacson, S., \& Briscoe, K. (1993). A naturalistic study of Ghostwriter use in after-school and school settings. A report prepared for the Children's Television Workshop.

Davidson, L. Y. J., Richardson, M., \& Jones, D. (2014). Teachers' perspective on using technology as an instructional tool. Research in Higher Education Journal, 24(1). http://www.aabri.com/copyright.html.

dos Santos, D. T., do Vale, D. T., \& Meloni, L. G. P. (2006). Digital TV and distance learning: Potentials and limitations. Proceedings - Frontiers in Education Conference, FIE. https://doi.org/10.1109/FIE.2006.322670

Ertmer, P. A., \& Ottenbreit-Leftwich, A. T. (2010). Teacher technology change: How knowledge, confidence, beliefs, and culture intersect, 42(3). www.iste.org/irte

Fadhilah, M., \& Sastramiharja, U. (2019). Distance learning in Thailand. Unpublished manuscript, Universitas Pendidikan Indonesia.

Fell, E., \& Lukianova, N. (2018). Communication spaces in the twenty-first century: Newsrooms, websites and garages. European Journal of Communication, 33(2), 227-233. https://doi.org/10.1177/0267323118761081

Hargreaves, A. (2000). Four ages of professionalism and professional learning. Teachers and Teaching: Theory and Practice. 
Hatch, A. J. (2002). Doing qualitative research in education settings (A. J. Hatch, Ed.). State University of New York Press, Albany.

Huang, H.-C., \& Eskey, D. E. (1999). The effects of closed-captioned television on the listening comprehension of intermediate English as a second language (ESL) students. Journal of Educational Technology Systems, 28(1), 75-96.

Hubbard, B. (2004). Literacy today comment. Literacy Today, 33, 3-3.

Janesick, V. (2004). Stretching exercises for qualitative researchers. Sage

Publications.

Kendeou, P., Lynch, J., van den Broek, P., Espin, C., White, M., \& Kremer, K. (2005). Developing successful readers: Building early comprehension skills through television viewing and listening. Early Childhood Education Journal, 33(2), 91-98.

Koskinen, P., Wilson, R., \& Jensema, C. (1986). Using closed-captioned television in the teaching of reading to deaf students. American Annals of the Deaf, 131(1), 43-46.

Kucirkova, N., Evertsen-Stanghelle, C., Studsrød, I., Jensen, I. B., \& Størksen, I. (2020a). Lessons for child-computer interaction studies following the research challenges during the covid-19 pandemic. International Journal of Child-Computer Interaction, 26. https://doi.org/10.1016/j.ijcci.2020.100203

Lawless, K. A., \& Pellegrino, J. W. (2007). Professional development in integrating technology into teaching and learning: Knowns, unknowns, and ways to pursue better questions and answers. Review of Educational Research, 77(4), 575-614. https://doi.org/10.3102/0034654307309921

Lin, P. M. S., \& Siyanova, A. (2014). Internet television for L2 vocabulary learning. In D. Nunan \& J. C. Richards (Eds.), Language learning beyond the classroom (pp. 149-158). Routledge.

Linebarger, D. L., \& Taylor-Piotrowski, J. L. (2006). "Pinky Dinky Doo?" Evaluating the education impact and appeal of Pinky Dinky Doo on preschool children. University of Pennsylvania, Children's Media Lab.

Linebarger, D., \& Wainwright, D. (2006). Television can teach: Elements of effective educational television. Annenberg School for Communication, University of Pennsylvania.

Malaikosa, C. A., \& Taopan, L. L. (2020). Teaching English at Junior High School in Indonesian Rural Area: The Implementation of Scientific Approach. Lensa: Kajian Kebahasaan, Kesusastraan, Dan Budaya, 10(2), 206. https://doi.org/10.26714/lensa.10.2.2020.206-217

Ma'rifah, U., Masrifah, N., \& Arifani, Y. (2021). Technological use in EFL instruction: Investigating teachers' pedagogical beliefs and students' learning engagement. Lensa: Kajian Kebahasaan, Kesusastraan, Dan Budaya, 11(1), 17. https://doi.org/10.26714/lensa.11.1.2021.17-32 Megawati, F., Hasanah, F. N., Aulina, C. N., Avivi, M., \& Muntiari, N. S. (2020). How confident are EFL prospective teachers toward 
technology? Lensa: Kajian Kebahasaan, Kesusastraan, Dan Budaya, 10(2), 137. https://doi.org/10.26714/lensa.10.2.2020.137-151

Michael Cohen Group. (2007). Children, families and media: A benchmark. Michael Cohen Group.

Moses, A. M. (2008). Impacts of television viewing on young children's literacy development in the USA: A review of the literature. Journal of Early Childhood Literacy, 8(1), 67-102. https://doi.org/10.1177/1468798407087162

Rideout, V. , V. E. \& W. E. (2003). Zero to six: Electronic media in the lives of infants, toddlers and preschoolers. Henry J. Kaiser Family Foundation.

Schneider, S. L., \& Council, M. L. (2021). Distance learning in the era of covid-19. Archives of Dermatological Research, 313(5), 389-390. https://doi.org/10.1007/s00403-020-02088-9

Singer, D. G. (2002). Sesame street: Still going and growing. PsycCRITIQUES, 47(4), 475-478.

Srivastava, J., Singh, Akanksha (2020). Paradigm shifting from classroom education to online classes during covid-19 pandemic. Journal in Management and Social Science, 8(06).

Stelitano, L., Doan, SY., Woo Ashley, Diliberti, M., Kaufman, J. H., \& Henry, D. (2020). The Digital Divide and COVID-19: Teachers' Perceptions of Inequities in Students' Internet Access and Participation in Remote Learning. Data Note: Insights from the American Educator Panels. RAND Corporation.

Stipp, H. (2003). How children can learn from television. Journal of Applied Developmental Psychology, 3(24), 363-365.

Sutherland, K. (2004). What's on the box? Rattler, 70, 13-15.

Tafazoli, D. (2021). CALL teachers' professional development amid the covid-19 outbreak: A qualitative study. Computer-Assisted Language Learning Electronic Journal (CALL-EJ). https://www.researchgate.net/publication/350604667

Tortermvasana, K. (2020). 17 new digital channels sequenced for education. https://www.bangkokpost.com/thailand/general/1917656/17new-digital-channels-sequenced-for-education

van Lommel, S., Laenen, A., \& D’Ydewalle, G. (2006). Foreign-grammar acquisition while watching subtitled television programmes. British Journal of Educational Psychology, 76(2), 243-258. https://doi.org/10.1348/000709905X38946

Webb, S. (2015). Extensive viewing: language learning through watching television. In Language learning beyond the classroom (pp. 159-168). Routledge.

Yin, R. K. (2009). Case study research: Design and methods (4 ${ }^{\text {th }}$ ed.). Sage. 